\title{
Two divergent leptin paralogues in zebrafish (Danio rerio) that originate early in teleostean evolution
}

\author{
Marnix Gorissen ${ }^{1}$, Nicholas J Bernier ${ }^{2}$, Sander B Nabuurs ${ }^{3}$, Gert Flik ${ }^{1}$ and Mark O Huising ${ }^{1,4}$ \\ ${ }^{1}$ Department of Animal Physiology, Faculty of Science, Radboud University Nijmegen, Heyendaalseweg 135, 6525 AJ Nijmegen, The Netherlands \\ ${ }^{2}$ Department of Integrative Biology, University of Guelph, Guelph, Ontario, N1G 2W1, Canada \\ ${ }^{3}$ Center for Molecular and Biomolecular Informatics (CMBI), Nijmegen Center for Molecular Life Sciences (NCMLS), Radboud University Nijmegen, \\ PO Box 9101, 6500 HB Nijmegen, The Netherlands \\ ${ }^{4}$ The Clayton Foundation Laboratories for Peptide Biology, Peptide Biology Laboratories, The Salk Institute for Biological Studies, 10010 North Torrey Pines Road, \\ La Jolla, California 92037, USA \\ (Correspondence should be addressed to M Gorissen; Email: m.gorissen@science.ru.nl)
}

\begin{abstract}
We describe duplicate leptin genes in zebrafish (Danio rerio) that share merely $24 \%$ amino acid identity with each other and only $18 \%$ with human leptin. We were also able to retrieve a second leptin gene in medaka (Oryzias latipes). The presence of duplicate leptin genes in these two distantly related teleosts suggests that duplicate leptin genes are a common feature of teleostean fishes. Despite low primary sequence conservation, we are confident in assigning orthology between mammalian and zebrafish leptins for several reasons. First, both zebrafish leptins share their characteristic gene structure and display key features of conserved synteny with mammalian leptin genes. Secondly, the cysteine residues that make up leptin's single disulphide bridge are equally spaced in mammalian and zebrafish leptins and are unique among all members of the class-I helical
\end{abstract}

cytokine family. Thirdly, the zebrafish leptins cluster with other fish leptins and mammalian leptins in phylogenetic analysis, supported by high bootstrap values. Within the leptin cluster, leptin-b forms a separate clade with the leptin-b orthologue from medaka. Finally, our prediction of the tertiary structures shows that both leptins conform to the typical four $\alpha$-helix bundle structure of the class-I $\alpha$-helical cytokines. The zebrafish leptins are differentially expressed; the liver shows high leptin-a expression (in concordance with what we observed for carp leptins), while leptin-b is expressed at much lower levels, which are downregulated further upon fasting. The finding of duplicate leptin genes in teleosts adds to our understanding of the evolution of leptin physiology in the early vertebrate lineage.

Journal of Endocrinology (2009) 201, 329-339

\section{Introduction}

The positional cloning of the obese $(o b)$ gene in 1994 (Zhang et al. 1994), identified the factor responsible for the morbid obesity of $o b / o b$ mutant mice. This gene encodes a unique member of the class-I helical cytokine family, a $16 \mathrm{kDa}$ protein named leptin after the Greek root leptos for lean. It is made up of a characteristic four $\alpha$-helix bundle conformation (Zhang et al. 1997). The key role of leptin in the regulation of body weight and energy homeostasis is well established (Schwartz et al. 2000, Morton et al. 2006). Leptin circulates in the bloodstream in proportion to the amount of body fat and signals to the brain. A major site of action is the arcuate nucleus (ARC), which contains two distinct populations of leptinresponsive neurons. One set co-expresses neuropeptide $\mathrm{Y}$ and agouti-related protein, is orexigenic and is inhibited by leptin (Broberger et al. 1998), while the other expresses pro-opiomelanocortin and cocaine and amphetamine regulated transcript, is anorexigenic and is stimulated by leptin (Elias et al. 1998).
Zhang et al. (1994) addressed the evolution of leptin by hybridizing genomic DNA of vertebrates that originated early in vertebrate evolution, including teleost fish, with a murine $o b$ probe. Positive signals from teleost genomic DNA led them to conclude that leptin is highly conserved throughout the vertebrates. Despite the detection of leptinlike immunoreactivity in the blood and liver, it took more than a decade to characterize the first teleost leptin orthologue (Kurokawa et al. 2005, Huising et al. 2006a) or even amphibian leptin orthologues (Boswell et al. 2006, Crespi \& Denver 2006). No bona fide avian and reptilian leptin genes have been described to date (Huising et al. 2006b). Both fish and Xenopus leptins show a low degree of primary sequence conservation compared with human leptins (varying from 13 to $30 \%$ amino acid identity respectively). Although the mere presence of a leptin orthologue in teleost fish supports the notion of leptin's evolutionary conservation, leptin is among the class-I helical cytokines with the poorest sequence conservation throughout the vertebrate subphylum (Huising et al. 2006b). In fish, a major site of leptin 
Table 1 Primer sequences. Primer names that start with ' $Q$ ' indicate the primers used for qPCR

\begin{tabular}{|c|c|c|c|}
\hline & Accession number & Primer & Sequence $5^{\prime} \rightarrow 3^{\prime}$ \\
\hline \multicolumn{4}{|l|}{ Gene } \\
\hline \multirow[t]{4}{*}{ Leptin-a } & AM920658 & zf.leptin-a.fw & ATG CGT TTT CCA GCT СTC \\
\hline & & zf.leptin-a.rv & TCA GCA GAT TTT CAG CTG GTC \\
\hline & & Q-zf.leptin-a.fw & GAC TGC ACA CTG AAG GAA TC \\
\hline & & Q-zf.leptin.a.rv & GCA CTG TCC TCT AGA AAA GC \\
\hline \multirow[t]{4}{*}{ Leptin-b } & AM901009 & zf.leptin-b.fw & ATG AAG TCT TCA ATG ATT TTT TGC \\
\hline & & zf.leptin-b.rv & CAG AGA ATG AAT GTC TCA GCC \\
\hline & & Q-zf.leptin-b.fw & ATT GCT CGA ACC ACC ATC AG \\
\hline & & Q-zf.leptin-b.rv & GAT GTC AGG GCC GAA ATC AA \\
\hline \multirow{2}{*}{$40 S$ ribosomal protein S11 } & CA472846 & Q-40S.fw & AAA CAG CCC ACC ATC TTC CA \\
\hline & & Q-40S.rv & CTG TGA TAA CGA GGG AGC TTT TC \\
\hline \multirow[t]{2}{*}{$\beta$-actin } & AF025305 & Q-BACT.fw & CAA CAG GGA AAA GAT GAC ACA GAT \\
\hline & & Q-BACT.rv & CAG CCT GGA TGG CAA CGT \\
\hline
\end{tabular}

expression is the liver (Kurokawa et al. 2005, Huising et al. $2006 a$ ), which is rich in fat droplets and has therefore been suggested as an appropriate site to monitor adipose stores. Yet, our understanding of the contribution of leptin to the regulation of energy metabolism in fish is scant and a key role of leptin in the regulation of body weight and energy homeostasis in non-mammalian vertebrates has not been established thus far (Volkoff et al. 2005, Gorissen et al. 2006). In carp, hepatic leptin mRNA increases post-prandially, but not after fasting or feeding to satiation for up to 6 weeks (Huising et al. 2006a).

It is well known that teleost fish possess duplicate copies for a number of genes (Taylor et al. 2003, Volff 2005). Therefore, we searched the zebrafish genome database to see if leptin too occurs in duplicate. Here, we demonstrate duplicate leptin genes in zebrafish (Danio rerio). An earlier systematic search of the zebrafish genome database revealed a predicted leptin gene with high (61-62\%) amino acid identity to both carp leptin-a-I and leptin-a-II (accession number BN000830) now designated leptin-a (Huising et al. 2006a). We cloned this leptin gene, and a second substantially different and paralogous leptin gene in zebrafish. Both zebrafish leptin paralogues share $24 \%$ primary amino acid sequence identity with each other and 18\% with mammalian leptins. Zebrafish leptin-a shares high primary sequence conservation with both carp leptins (61-62\%); leptin-b, however, shares only $25 \%$ amino acid identity with both carp leptins. Despite these low identities, conservation of gene structure, tertiary structure, stable phylogenetic analysis, and synteny substantiate the unambiguous orthology of zebrafish leptin-a and leptin-b with mammalian leptins.

\section{Materials and Methods}

\section{Animals}

Zebrafish (D. rerio) were commercially obtained and reared in two liter tanks at $26^{\circ} \mathrm{C}$ with recirculating, u.v. treated, Nijmegen tap water. Eight fish were kept and fed with $2 \cdot 5 \%$

body weight Tetra-min (Tetra, Melle, Germany) each day. Eight other fish were not fed for 2 weeks. For the determination of leptin tissue distribution, fish were fed with $2 \cdot 5 \%$ body weight daily and killed $1 \mathrm{~h}$ after feeding. All fish were euthanized in a $0 \cdot 1 \%(\mathrm{w} / \mathrm{v}) 2$-phenoxyethanol solution. Animal experiments were performed in accordance with national legislation and approved by the ethical committee of the Radboud University Nijmegen.

\section{Identification of zebrafish leptin paralogues}

We screened the ENSEMBL zebrafish genome (www. ensembl.org) with several teleost leptin sequences, using the BLAST algorithm (Altschul et al. 1997). The initial screen revealed two leptin-like sequences, one of which was already predicted in an earlier screen of the zebrafish genome (third

Table 2 List of BLAST hits following comparison between zebrafish leptin-a (A) and leptin-b (B) to the non-redundant protein database (nr). BLAST hits are scored by an ' $E$ value', which applies statistical probability that the similarity between two sequences is based on stochastic events

\section{Species Description Evalue}

\section{Accession number}

$\mathrm{BN} 000380$

AJ868357

AJ868356

ABV 57772

AAZ66785

AY884210

AAY68394

AM901009

B

AM901009

AJ868356

AJ868357

ABV57772

BN000380

AAZ66785

$\begin{array}{lll}\text { Zebrafish } & \text { Leptin-a } & 5 \times 10^{-89} \\ \text { Common carp } & \text { Leptin-a-I } & 7 \times 10^{-49} \\ \text { Common carp } & \text { Leptin-a-II } & 2 \times 10^{-48} \\ \text { Goldfish } & \text { Leptin-a-II } & 2 \times 10^{-32} \\ \text { Channel catfish } & \text { Leptin } & 2 \times 10^{-14} \\ \text { Xenopus laevis } & \text { Leptin } & 6 \times 10^{-9} \\ \text { Tiger salamander } & \text { Leptin } & 9 \times 10^{-6} \\ \text { Zebrafish } & \text { Leptin-b } & 2 \times 10^{-5} \\ & & \\ \text { Zebrafish } & \text { Leptin-b } & 7 \times 10^{-58} \\ \text { Common carp } & \text { Leptin-a-II } & 5 \times 10^{-8} \\ \text { Common carp } & \text { Leptin-a-I } & 2 \times 10^{-7} \\ \text { Goldfish } & \text { Leptin-a-II } & 9 \times 10^{-7} \\ \text { Zebrafish } & \text { Leptin-a } & 9 \times 10^{-7} \\ \text { Channel catfish } & \text { Leptin } & 1 \times 10^{-4}\end{array}$


party annotation accession number: BN000830; Huising et al. 2006a). Using primers zf.leptin-a.fw, leptin-a.rv, and leptin-b.fw, leptin-b.rv (Table 1), based on these partial leptin sequences, two cDNA sequences were obtained from the liver and gonads respectively. RNA isolation, cDNA synthesis, cloning, and sequencing was carried out as previously described (Metz et al. 2005). Briefly, PCR products were ligated and cloned in TOP10 chemically competent Escherichia coli in the pCR4-TOPO vector (Invitrogen). Plasmid DNA was isolated with a Miniprep Kit (BioRad) and sequences were determined from both strands using the ABI prism big-dye terminator cycle sequencing ready reaction kit (Applied Biosystems, Foster City, CA, USA).

\section{Phylogenetic analysis}

Multiple sequence alignments were carried out using ClustalW (http://www.ebi.ac.uk/Tools/clustalw/; Thompson et al. 1994). A phylogenetic tree was constructed based on amino acid difference ( $p$-distance) with the neighbor-joining algorithm (pairwise deletion) in MEGA version 3.1 (Kumar et al. 2004). The reliability of the tree was assessed by bootstrapping, using 1000 replications. Only full-length coding sequences were used for analysis.

In order to determine synteny between the zebrafish leptin paralogues and human leptin, we mapped the upstream and downstream genes of leptin on the respective chromosomes of zebrafish and human using the ENSEMBL genome browser (www.ensembl.org).

\section{Modeling of tertiary structures}

The structure of human leptin (PDB entry 1AX8), which was resolved at $2 \cdot 4 \AA$ resolution (Zhang et al. 1997), was used as a template to build models of zebrafish leptin-a and leptin-b. Initial alignments were obtained from the PSIPRED fold recognition server (McGuffin \& Jones 2003). Side-chain rotamers were modeled using SCWRL3.0

A

$\begin{array}{lllllllllllllllllllll}1 & M & R & F & P & A & L & R & S & T & C & I & L & S & M & L & S & L & I & H & C\end{array}$

1 atgcgttttccagctctccgctcaacctgtattttgagcatgctcagtttgattcattgc

$\begin{array}{llllllllllllllllllllll}21 & I & P & V & H & Q & H & D & R & K & N & V & K & L & Q & A & K & T & I & I & V\end{array}$

61 attcccgttcatcagcatgaccggaaaatgtcaaactgcaggcaaagaccatcatcgtc

$\begin{array}{lllllllllllllllllllll}41 & R & I & R & E & H & I & D & G & Q & N & L & L & P & T & L & I & I & G & D & P\end{array}$

121 agaatcagggaacacattgacgggcaaatttacttccaacgctcatcattggggatcca

$\begin{array}{lllllllllllllllllllll}61 & G & H & Y & P & E & I & P & A & D & K & P & I & Q & G & L & G & S & I & M & E\end{array}$

181 ggacattatccagagattcccgctgacaaacccatccaagggctcggctccatcatggaa

$\begin{array}{lllllllllllllllllllll}81 & \mathrm{~T} & \mathrm{I} & \mathrm{N} & \mathrm{T} & \mathrm{F} & \mathrm{H} & \mathrm{K} & \mathrm{V} & \mathrm{L} & \mathrm{Q} & \mathrm{K} & \mathrm{L} & \mathrm{P} & \mathrm{N} & \mathrm{K} & \mathrm{H} & \mathrm{V} & \mathrm{D} & \mathrm{Q} & \mathrm{I}\end{array}$

241 accattaataccttccacaaggttcttcagaagcttccaataagcatgttgaccagata

$\begin{array}{lllllllllllllllllllll}101 & R & R & D & L & S & T & L & L & G & Y & L & E & G & M & D & C & T & L & K & E\end{array}$

301 cgccgagatctatccacacttctgggttacctggaaggcatggactgcacactgaaggaa

$\begin{array}{llllllllllllllllllllll}121 & S & T & N & G & K & A & L & D & A & F & L & E & D & S & A & S & Y & P & F & T\end{array}$

361 tcaacaaatgggaaagcgctggacgcttttctagaggacagtgcttcatatcccttact

$\begin{array}{lllllllllllllllllllll}141 & L & E & Y & M & T & L & N & R & L & K & Q & F & M & Q & K & L & I & D & N & L\end{array}$

421 ttagagtacatgactttaaacagactgaaacagtttatgcaaaagctgatcgataatctg

$161 \mathrm{D}$ Q $\mathrm{L}$ K $\mathrm{I}$ C *

481 gaccagctgaaaatctgctga

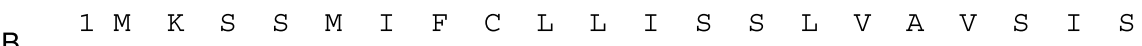

1 atgaagtcttcaatgatttttgcttgttaatatcatccctggtggccgtgagcatcagt

$\begin{array}{lllllllllllllllllllll}21 & R & P & T & A & P & E & D & R & I & R & I & I & A & R & T & T & I & S & R & I\end{array}$

61 cgacccacggctcccgaagacaggatacgaatcattgctcgaaccaccatcagccgatt

$\begin{array}{lllllllllllllllllllll}41 & K & K & I & K & D & E & H & F & Q & M & S & P & E & I & D & F & G & P & D & I\end{array}$

121 aaaaaatcaaagatgagcacttccagatgtctccagagattgatttcggccctgacatc

$\begin{array}{lllllllllllllllllllll}61 & D & N & P & I & D & G & L & S & S & V & L & S & Y & L & S & Y & L & Q & L & R\end{array}$

181 gacaaccccattgatggtctcagttctgtcttgagttacttgagttacctgcagttgcgg

$\begin{array}{lllllllllllllllllllllllllllllll}81 & \mathrm{~L} & \mathrm{H} & \mathrm{V} & \mathrm{P} & \mathrm{P} & \mathrm{A} & \mathrm{Q} & \mathrm{H} & \mathrm{L} & \mathrm{Q} & \mathrm{Q} & \mathrm{V} & \mathrm{Q} & \mathrm{I} & \mathrm{D} & \mathrm{L} & \mathrm{E} & \mathrm{T} & \mathrm{L} & \mathrm{L}\end{array}$

241 ttgcatgttcctccagctcagcacctacagcaggtccagatagacttagagactctcctg

$\begin{array}{llllllllllllllllllllll}101 & R & T & L & E & E & L & A & V & S & Q & G & C & P & L & P & N & P & E & T & P\end{array}$

301 aggacactggaggaactggccgtctcacagggatgccctctacccaatcccgagaccccg

$\begin{array}{llllllllllllllllllllll}121 & V & H & K & E & E & T & A & F & P & V & T & S & N & Y & L & H & L & L & E & L\end{array}$

361 gtgcataaagaagaaacagccttccccgtcacctccaactacctgcacctcctggagctc

$\begin{array}{lllllllllllllllllllll}141 & Q & R & F & L & E & K & L & C & L & N & I & D & K & L & K & Y & C & K & D & T\end{array}$

421 cagaggttcctggagaagctctgcctcaacatagacaaactgaaatactgcaaagataca

161 D $V$ A $E$ T $F$ I $L$ *

481 gatgtggctgagacattcattctctga

Figure 1 cDNA and deduced amino acid sequence of the coding sequence of zebrafish leptin-a and leptin-b. Accession numbers are AM920658 and AM901009 respectively. 
Helix-A

Zebrafish leptin-a Zebrafish leptin-b Carp leptin-a-I Carp leptin-a-II Human leptin

Zebrafish leptin-a Zebrafish leptin-b Carp leptin-a-I Carp leptin-a-II Human leptin

Zebrafish leptin-a Zebrafish leptin-b Carp leptin-a-I Carp leptin-a-II Human leptin

Zebrafish leptin-a Zebrafish leptin-b Carp leptin-a-I Carp leptin-a-II Human leptin
MRFPALR-STCILSMLSLIHCIPVHQHDRKN-VKLQAKTIIVRIREHIDG-QNLLPTLII 57 MKSSMIF-CLLISSLVAVSISRPTAPE---DRIRIIARTTISRIKKIKDEHFQMSPEIDF 56 MYFSALL-YPCILAMLSLVHGIPIHSDSLKNLVKLQADTIIIRIKDHNAE-LKLYPKLLI 58 MYFSVLL-YPCILGMLSLVHAI PVHPDSLKNLVKLQADTIILRIKDHNEK-LKLSPKLLI 58 MHWGTLCGFLWLWPYLFYVQAVPIQKVQ--DDTKTLIKTIVTRINDISHTQSVSSKQKVT 58

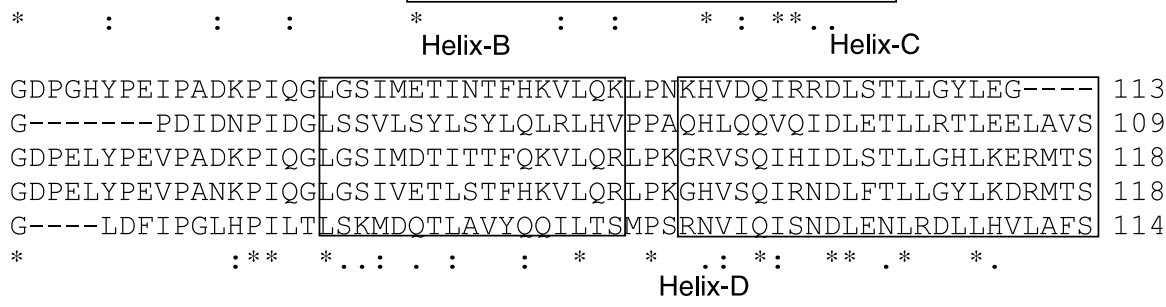

MDCTLKESTNGKALDAFLEDSASYPFTLEYMTLNRLKQFMQKLIDNLDQLKIC------- 166 QGCPLPNPE-----TPVHKEETAFPVTSNYLHLLELQRFLEKLCLNIDKLKKYKDTDVAE 164 MHCTSKEPANGRALDAFLEDNATHHITVRYLALDRLKQFMQKLLVNLDQLKSC------- 171 MRCTLKEPANERSLDAFLENNATHHITFGFLALDRLKQFMQKLIVNLDHLKSC------ 171 KSCHLPWASGLETLDSLGGVLEASGYSTEVVALSRLQGSLQDMLWQLDLSPGC------- 167

$\begin{array}{ll}* & \\ & \\ ---- & \\ \text { TFIL } 168 \\ ---- \\ ---- \\ ----\end{array}$

Figure 2 Multiple sequence alignment of zebrafish leptins, carp leptins and human leptin. Asterisks indicate amino acids that are conserved in all sequences, whereas colons and dots reflect decreasing levels of amino acid similarity. The four $\alpha$-helices (A-D) were inferred from human leptin and are boxed in the alignment. The cysteine residues that form leptin's single disulphide bridge are shaded. Accession numbers: zebrafish leptin-a: AM920658, zebrafish leptin-b: AM901009, carp leptin-a-I: AJ868357, carp leptin-a-II: AJ868356, human leptin: P41159.

(Canutescu et al. 2003). Both models were refined in YASARA using the YAMBER2 forcefield (Krieger et al. 2004). Coordinate files are available from the authors on request.

\section{Expression of zebrafish leptins}

Relative expression of zebrafish leptin paralogues was assessed by real-time qPCR. We designed primers using primer express software (Table 1; Applied Biosystems). Five microliters cDNA and $300 \mathrm{nM}$ forward and reverse primers were added to $12.5 \mu \mathrm{l} \mathrm{SYBR}$ Green Mastermix (Applied
Biosystems). The total volume was adjusted to $25 \mu \mathrm{l}$ with deionized $\mathrm{H}_{2} \mathrm{O}$. qPCR $\left(10 \min 95^{\circ} \mathrm{C}, 40\right.$ cycles of $15 \mathrm{~s} 95^{\circ} \mathrm{C}$ and $1 \mathrm{~min} 60^{\circ} \mathrm{C}$ ) was carried out using a GeneAmp 7500 sequence detection system (Applied Biosystems). Different samples were run on a single plate. Dual internal standards (40S ribosomal protein S11 and $\beta$-actin) were incorporated in all measurements and results were confirmed to be very similar following standardization to either gene. Only results relative to $40 \mathrm{~S}$ are shown. Constitutive expression of leptin in zebrafish organs and tissues was corrected for primer efficiency and plotted as a ratio between target gene versus

Table 3 Percentages for amino acid sequence identities between vertebrate leptin sequences

\begin{tabular}{|c|c|c|c|c|c|c|c|c|c|}
\hline & $\begin{array}{l}\text { Zebrafish } \\
\text { leptin-a }\end{array}$ & $\begin{array}{l}\text { Zebrafish } \\
\text { leptin-b }\end{array}$ & $\begin{array}{l}\text { Carp } \\
\text { leptin-a-I }\end{array}$ & $\begin{array}{l}\text { Carp } \\
\text { leptin-a-II }\end{array}$ & $\begin{array}{l}\text { Clawed } \\
\text { frog }\end{array}$ & Human & Mouse & Dog & Cow \\
\hline Zebrafish leptin-a & 100 & & & & & & & & \\
\hline Zebrafish leptin-b & 24 & 100 & & & & & & & \\
\hline Carp leptin-a-I & 64 & 25 & 100 & & & & & & \\
\hline Carp leptin-a-II & 63 & 25 & 81 & 100 & & & & & \\
\hline Clawed frog & 24 & 13 & 27 & 27 & 100 & & & & \\
\hline Human & 19 & 19 & 21 & 23 & 35 & 100 & & & \\
\hline Mouse & 21 & 19 & 23 & 25 & 34 & 83 & 100 & & \\
\hline Dog & 19 & 18 & 22 & 23 & 33 & 80 & 78 & 100 & \\
\hline Cow & 20 & 19 & 23 & 25 & 34 & 84 & 83 & 88 & 100 \\
\hline
\end{tabular}




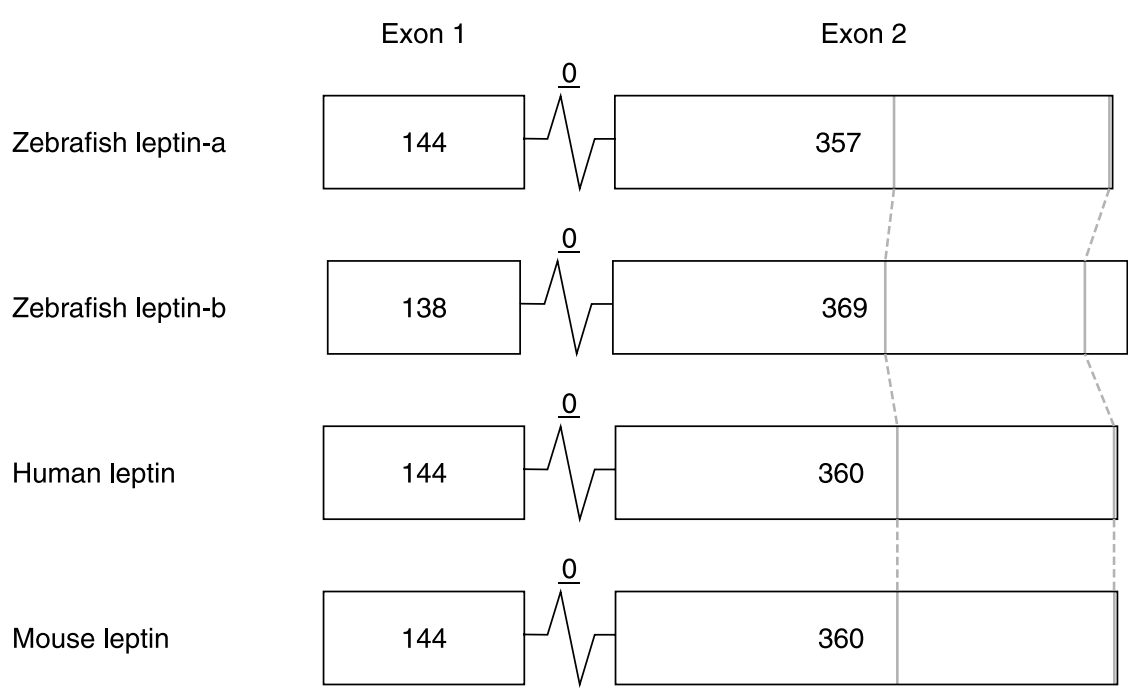

Figure 3 The gene structures of zebrafish leptins and mammalian leptins are conserved. Boxes represent coding exons only and are drawn to scale. Numbers inside the boxes reflect exon sizes in nucleotides. The intron phase is indicated with underlined numbers.

reference gene. Relative expression of leptin paralogues in the liver following fasting was corrected for primer efficiency and reference gene, and plotted relative to controls.

\section{Results}

Zebrafish expresses duplicate and divergent leptin genes

A systematic BLAST search of the ENSEMBL zebrafish genome database with mammalian leptin sequences revealed two partial leptin sequences, one of which represented leptin-a (already described by Huising et al. 2006a), the other represented a new leptin-like orthologue that we named leptin-b. The (automated) genomic sequences were corrected by hand for correct splice sites and the obtained sequences were used in a homology cloning approach to identify both leptin cDNA sequences. Protein-protein BLAST (BLASTp) showed significant hits with other fish leptins (Table 2). The cDNA- and deduced amino acid sequences of zebrafish leptins are shown in Fig. 1. Both leptin-a and leptin-b are comparable in size, 166 and 168 amino acids respectively, both with a predicted signal peptide of 20 amino acids. Previously, we described two highly similar leptin genes in common carp (Huising et al. 2006a) which we designated leptin-I and leptin-II. These carp leptin paralogues are likely the result of the recent genome duplication $\sim 16$ Mya that led to the tetraploidization of the common carp genome (Larhammar \& Risinger 1994). Our results suggest that zebrafish leptin-a and leptin-b are the result of the ancient genome duplication that teleost fish experienced (Taylor et al. 2003, Volff 2005). Therefore, we amend the names of the previously described carp leptins to
A

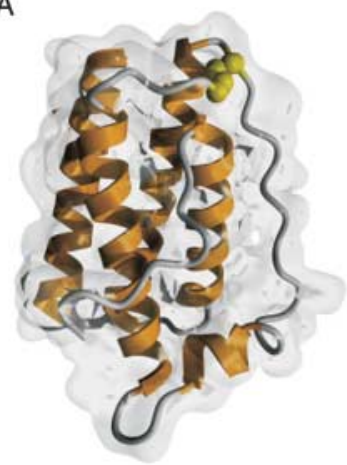

B

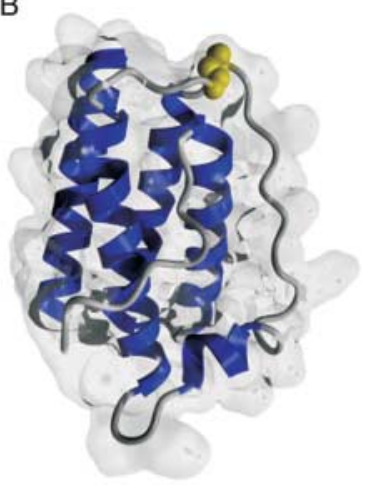

C

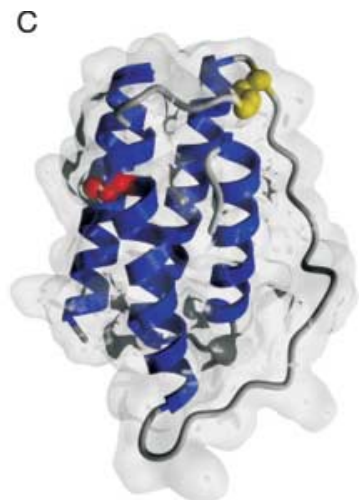

Figure 4 Protein models of the duplicate zebrafish leptins and human leptin. Zebrafish leptin-a (B), leptin-b $(C)$ and human leptin $(A)$ were modeled on the human leptin crystal structure and conform to the four $\alpha$-helix bundle adopted by human leptin. In yellow the single disulphide bridge that stabilizes leptin's tertiary structure, in red the third cysteine of zebrafish leptin-b. 


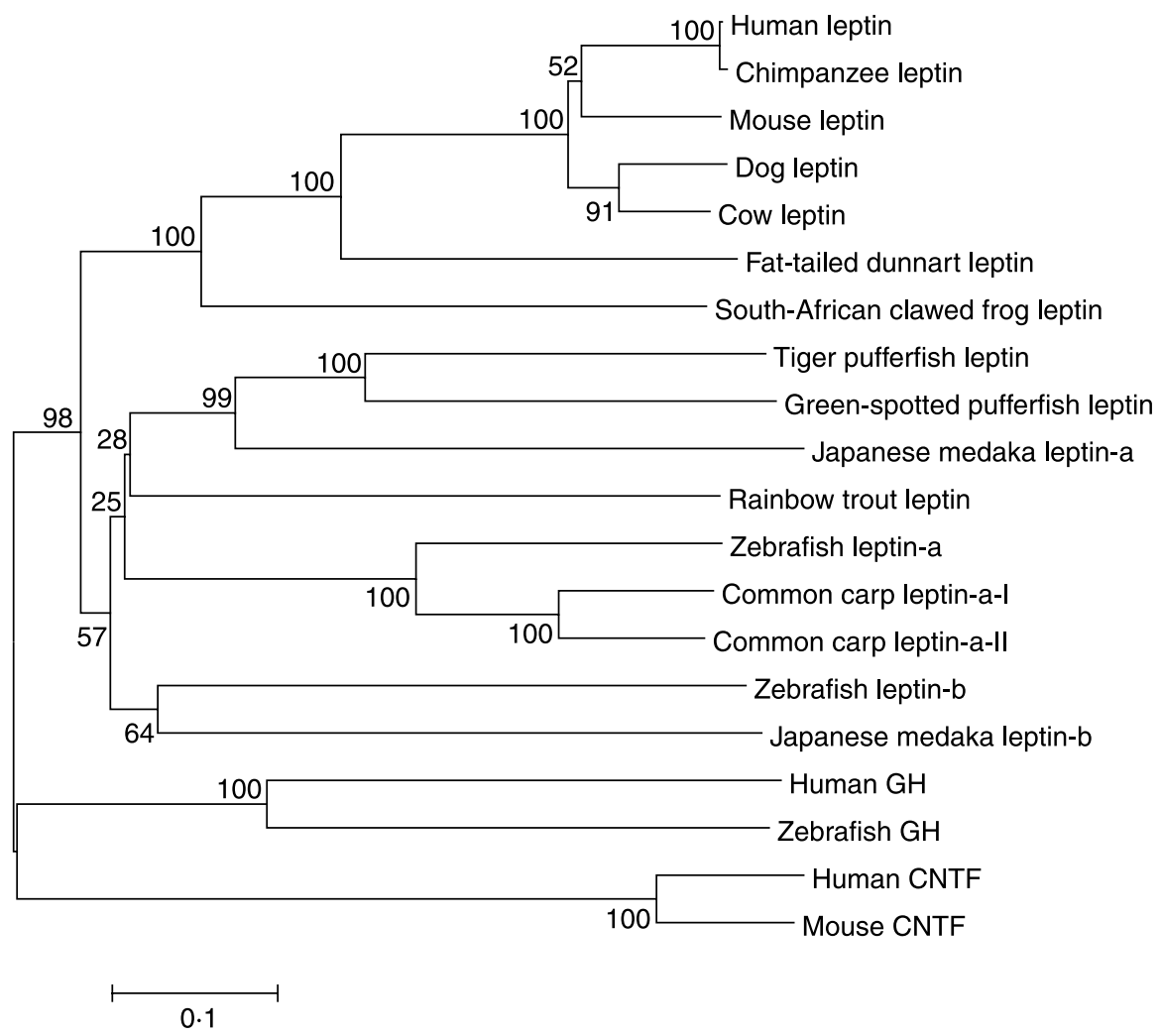

Figure 5 Phylogenetic tree of vertebrate leptins. Numbers at the branches reflect the confidence level as obtained by bootstrapping (1000 replications). GH and ciliary neurotrophic factor (CNTF; both class-I helical cytokines) were included as out-group. Only full length sequences were used for phylogenetic analysis. Accession numbers are as follows: chimpanzee leptin: O02750, human leptin: P41159, mouse leptin: P41160, dog leptin: O02720, cow leptin: P50595, fat-tailed dunnart leptin: AF159713, South-African clawed frog leptin: AY884210, carp leptin-a-I: AJ836745, carp leptin-a-II: AJ836744, zebrafish leptin-a: AM920658, rainbow trout leptin: AB354909, zebrafish leptin-b: AM901009, medaka leptin-a: AB193548, medaka leptin-b: BN001183, tiger pufferfish leptin: AB193547, green-spotted pufferfish leptin: AB193549, human GH: P01241, zebrafish GH: Q1JQ34, human CNTF: P26441, mouse CNTF: P51642.

leptin-a-I and leptin-a-II. We want to stress that the low amino acid identity of the leptin proteins between fish and mammals serves as a reminder that we assign the name leptin solely based on the structural similarities described above. Orthologous proteins do not by default share analogous roles, particularly proteins that share so little of their primary amino acid sequences as teleostean and mammalian leptins do (Huising et al. 2006a).

\section{Characteristics of zebrafish leptins}

The amino acid identity between zebrafish leptin-a and leptin-b is $24 \%$. Zebrafish leptin-a is more similar $60 \%$ primary amino acid sequence identity) to carp leptin-a-I and leptin-a-II. The identity between zebrafish leptin-b and carp leptins is, at only $25 \%$, marginally higher than the identity between leptin-b and mammalian leptins (19\%; Fig. 2 and
Table 3). The cysteine residues that make up leptin's single disulphide bridge, connecting the carboxy-terminal ends of $\alpha$-helices $C$ and D are conserved. Both zebrafish leptin genes are encoded by two exons that are similar in size compared with mammalian leptins (Fig. 3). Zebrafish leptin genes possess a short intron, with consensus $5^{\prime}$ donor (gt) and $3^{\prime}$ acceptor (ag) splice sites. The intron phase indicates whether the intron is situated in between triplets (phase 0), or following the first or second base of a triplet (phase 1 or phase 2 respectively). The intron phase for both zebrafish leptins is identical to the intron phase of mammalian leptins: phase 0 .

Our models of both zebrafish leptins conform to the typical four $\alpha$-helix conformation (up-up-down-down) of human leptin (Fig. 4), indicating that the tertiary structures of zebrafish leptins are comparable with mammalian leptins. In contrast to all other leptin sequences, leptin-b contains an additional cysteine residue in helix-D. From the position of 


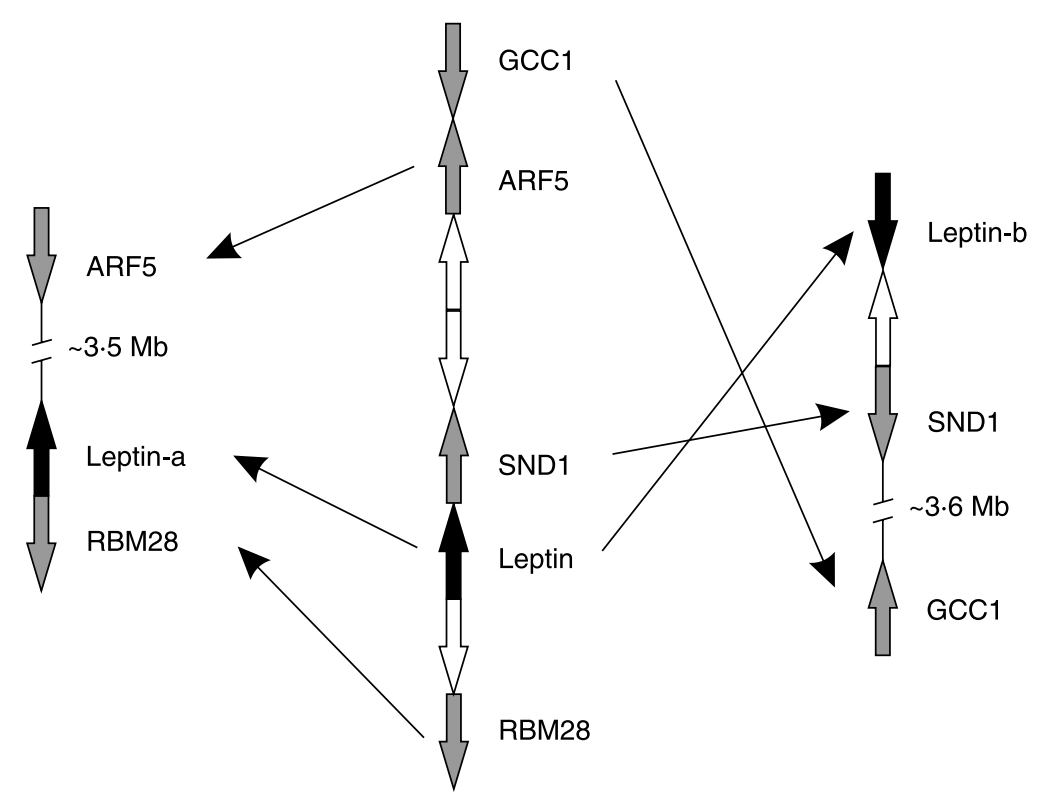

Figure 6 The synteny between the human leptin locus and both zebrafish leptin loci is conserved. A comparison between the human leptin locus $(7 \mathrm{q} 32.1)$ and the zebrafish leptin loci (located on chromosome 18 and 4 respectively) reveals that adjacent to both zebrafish leptins there are multiple genes that lie adjacent to human leptin. Arrows reflect genes, the direction of the arrow the orientation of the gene. Black arrows represent leptin orthologues, grey arrows represent genes in synteny in the human and zebrafish leptin loci. Genes are not drawn to scale, nor is intergenic space included. ARF5, ADP-ribosylation factor 5; RBM28, RNA binding protein motif 28; SND1, staphylococcal nuclease domain-containing protein 1; GCC1, GRIP and coiled-coil domain-containing 1.

this cysteine (indicated in red in Fig. 4) we cannot draw firm conclusions regarding the availability of this cysteine to form intermolecular disulphide bridges.

\section{Phylogeny of zebrafish leptins}

The zebrafish leptin paralogues cluster together with other vertebrate leptin genes, supported by a high bootstrap value (98), supporting the orthology of both zebrafish leptins with mammalian leptins (Fig. 5). Within the leptin cluster, the overall topology of the phylogenetic tree adheres to the established pattern of evolution, as the teleost leptin cluster branches off before the separation of the amphibian and mammalian cluster. Within the mammalian leptin cluster, the only known sequence of a marsupial leptin (that of the fattailed dunnart) branches outside the leptin sequences of placental mammals. In the teleost leptin cluster, zebrafish leptin-a and the carp leptins form a separate clade. We also screened other fish databases in order to assess the presence of leptin-b orthologues in other teleost fish species. Using the zebrafish leptin-b sequence in a BLAST search of the ENSEMBL medaka (Oryzias latipes) genome, we retrieved a leptin-b orthologue with $28 \%$ amino acid identity to zebrafish leptin-b (BN001183). Zebrafish leptin-b and medaka leptin$\mathrm{b}$ form a separate clade within the teleost leptin cluster.
Both zebrafish leptin genes share synteny with a human leptin

To further substantiate the orthology of the zebrafish leptin paralogues to mammalian leptins, we compared the synteny of both zebrafish leptins with human leptin. Synteny refers to the order and orientation of the genes of chromosomes and tends to be a conserved feature across species. For each zebrafish leptin, several genes are found in synteny with mammalian leptin (Fig. 6). The leptin-a gene of zebrafish is located next to RNA binding motif 28 (RBM28), as is the human leptin gene. In close proximity to leptin-b, Staphylococcal nuclease domain-containing protein 1 and GRIP and coiled-coil domain-containing 1 are found - again, these are also found in close proximity to human leptin.

\section{Constitutive expression of zebrafish leptins}

Zebrafish leptins (Fig. 7) show a differential expression pattern. Whereas leptin-a is prominently expressed in the liver, in accordance with previous observations of carp leptina-I and -II, leptin-b is not. Leptin-a is expressed at higher levels than leptin-b in most organs except the ovary, which is a major site of leptin-b mRNA expression. 


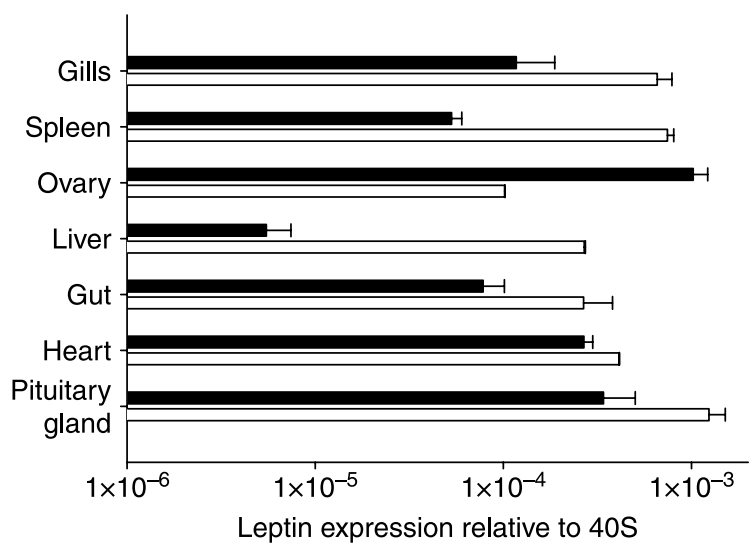

Figure 7 Basal expression of leptin-a (open bars) and leptin-b (closed bars). Leptin-a and leptin-b are constitutively expressed in all organs investigated. Bars represent the mean value of four individual zebrafish. Error bars indicate S.E.M. Note the logarithmic scale of the $x$-axis.

\section{Leptin $m R N A$ expression after fasting for 1 week}

To gain insight into possible physiological functions of the leptin paralogues, we investigated leptin mRNA expression after fasting for 1 week. Leptin-a mRNA levels show no significant response to fasting for 1 week (Fig. 8). By contrast, hepatic leptin-b expression is significantly downregulated $(P<0 \cdot 05)$ after 1 week of food deprivation.

\section{Discussion}

Zebrafish possesses duplicate leptin genes, coding for leptin-a and leptin-b, which differ substantially from each other $(24 \%$ amino acid identity). It is possible that a major genome duplication that took place $\sim 300$ Mya in the early fish lineage (Taylor et al. 2003, Volff 2005) resulted in duplicated leptins. The discovery of a leptin-b orthologue in the Japanese medaka supports this view as zebrafish and medaka represent two distant teleost lineages, the Cypriniformes and the Beloniformes respectively, which shared their last common ancestor $~ 296$ Mya (Hoegg \& Meyer 2005; Fig. 9). In contrast, from the primary sequence identity and phylogenetic analysis, it follows that the duplicate carp leptins that we described recently (Huising et al. 2006a) likely resulted from the more recent genome duplication in carp ( $\sim 16$ Mya; Larhammer \& Risinger 1994) and represent the duplicated orthologues of zebrafish leptin-a. Therefore, we propose that these carp leptin sequences should be renamed leptin-a-I and leptin-a-II. This observation, combined with the identification of leptin-b in two distantly related fish substantiates the view that more bony fishes express orthologues of leptin-b. Gene duplications, and genome duplications in particular, are considered the main thrust contributing to the expansion of an organism's gene repertoire, as the presence of newly duplicated paralogues allows one of the two paralogues of a pair to drift and on occasion acquire a novel function while the original function is maintained by the other. Gene duplications in the teleost lineage are common, and there are several well-documented examples of large scale (often referred to as whole) genome duplication events. A major genome duplication (Taylor et al. 2003, Volff 2005) is thought to have yielded several duplicate class-I helical cytokines, viz. duplicate interleukin-11 (Huising et al. 2005), IL-12p35 (Huising et al. 2006b), CXCL12 (Huising et al. 2004), and cytokine receptor (IL12p40; Huising et al. 2006c) genes. We could not retrieve a leptin-b orthologue from the available pufferfish genomes (tiger pufferfish; Takifugu rubripes, and the green spotted pufferfish; Tetraodon nigroviridis). While one reason for our inability to retrieve leptin-b orthologues from these species may be that their respective genomes are incomplete, it is also possible that the Tetraodontoformes may have lost leptin-b from their gene repertoire. In the genome of $T$. nigroviridis, we found two regions with a conserved genomic neighborhood compared with human leptin. Indeed, only one of these loci carries a leptin orthologue, which is strong support for the hypothesis that the pufferfish lineage does not possess duplicate leptin genes.

Recently, multiple entries have been submitted in the EMBL database for several fish leptin orthologues that all share 97-99\% sequence similarity at the nucleotide level (AY497007, AY547279, AY547322, AY551335, AY551336, AY551337, AY551338, AY551339, AY551340, DQ784814, DQ784815, DQ784816). Non-synonymous substitutions are subject to selection as they result in differences in amino acid sequence, whereas synonymous substitutions are generally not. Therefore, the almost complete absence of synonymous substitutions (over 97\% nucleotide identity) between these deposited 'teleost' leptin sequences and mammalian leptin sequences would represent an extraordinary and very unlikely

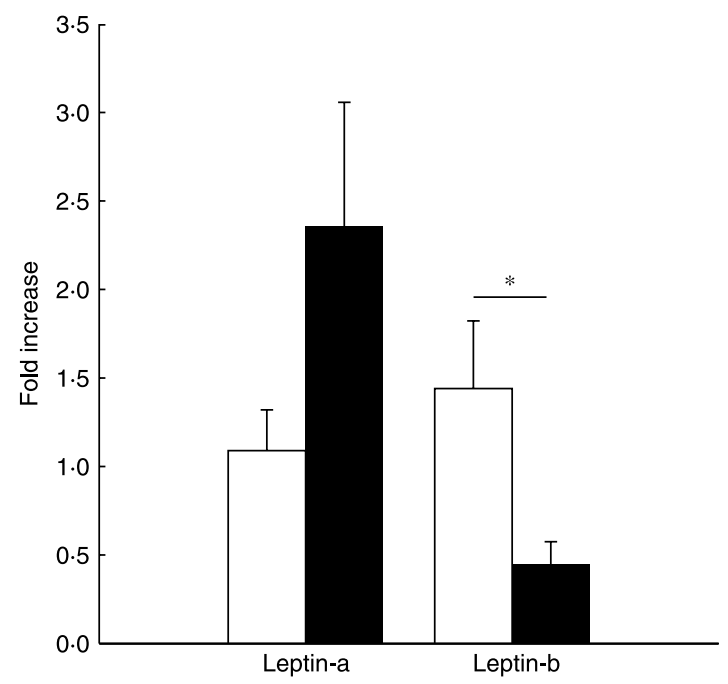

Figure 8 Leptin-a and leptin-b mRNA expression after 1 week fasted (closed bars) and fed (control; open bars) zebrafish. Leptin-b mRNA decreases significantly (*: $P<0 \cdot 05)$ after fasting for 1 week. Bars represent the mean value, error bars indicate S.E.M. 


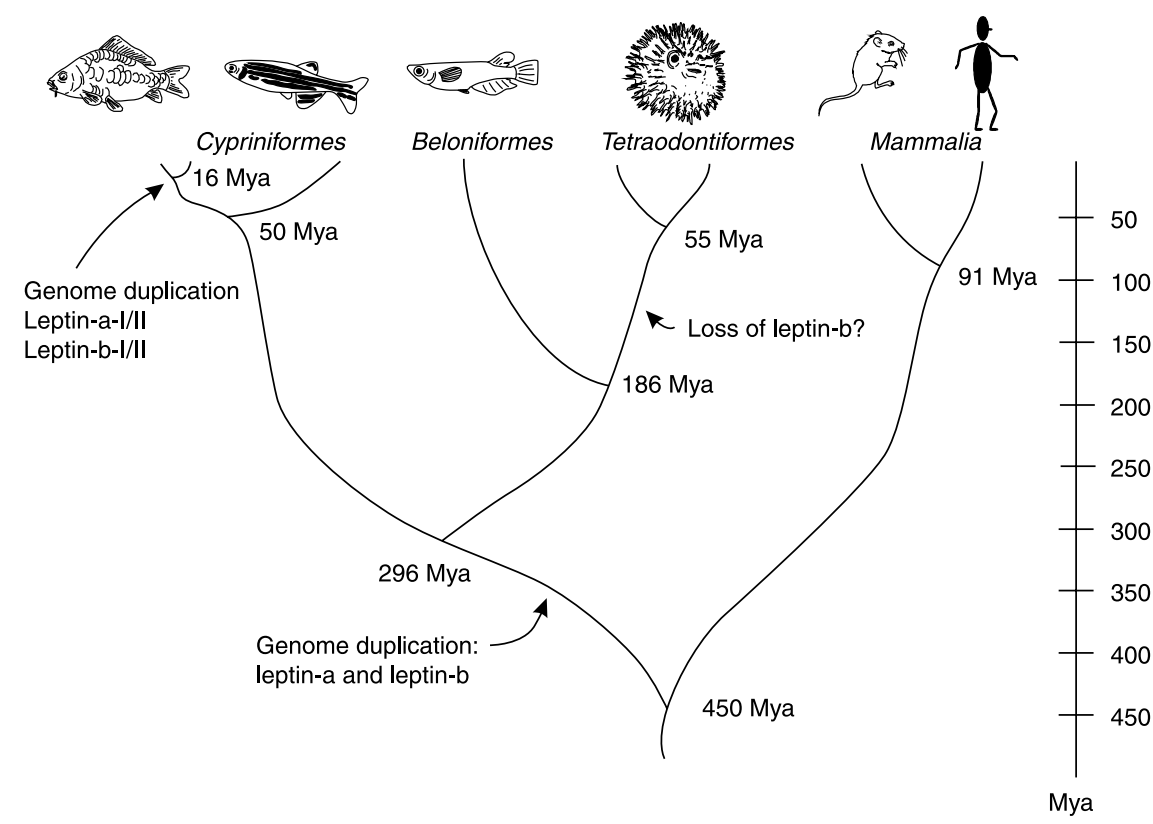

Figure 9 General phylogenetic tree of vertebrate evolution. Mammals and teleosts shared their last common ancestor $\sim 450$ Mya. The finding of duplicate leptin paralogues in the medaka (Beloniformes) and zebrafish (Cypriniformes) dates the duplication event that gave rise to the duplicated leptins to $\sim 296 \mathrm{Mya}$, as these species shared their last common ancestor at that time point. The tetraploidization of the carp genome $(\sim 16 \mathrm{Mya})$ is likely the event that gave rise to paralogous leptin-a-I and leptin-a-II genes in carp. Divergence estimates are based on: (Zardoya \& Doadrio 1999, Hedges 2002, Hoegg \& Meyer 2005, Volff 2005).

example of evolutionary convergence, as teleosts and mammals shared their last common ancestor over 450 million years ago. Instead, these sequences should be regarded as artifacts. A similar situation unfortunately has occurred for chicken leptin that was reported to be highly similar to mouse leptin by two independent groups (Taouis et al. 1998, Ashwell et al. 1999). Subsequent studies have raised concerns regarding the validity of these published chicken leptin sequences (Friedman-Einat et al. 1999, Doyon et al. 2001, Huising et al. 2006b, Sharp et al. 2008).

Despite the relatively low amino acid conservation that was previously noted for other teleost leptins, we are confident to assign orthology between zebrafish leptin-b and mammalian leptins, supported by several key features of zebrafish leptin-b. First, both zebrafish leptin genes are encoded by two exons of comparable size to the ones coding for mammalian leptins. Vertebrate class-I cytokines are typically encoded by three or more (usually five) exons. In fact, the only class-I helical cytokine other than a leptin composed of two exons is ciliary neurotrophic factor (Huising et al. 2006b), which differs substantially in primary sequence as well as gene structure from a leptin. Furthermore, the spacing of the two cysteine residues that make up leptin's single disulphide bridge is unique among class-I helical cytokines (Huising et al. 2006b). Thirdly, the stable phylogenetic clustering of the zebrafish leptin sequences with other fish leptins, as with the mammalian leptins, supports the unambiguous identity of the two zebrafish leptins. Finally, the predicted tertiary structure of zebrafish leptin-b, conforming to the human crystal structure of leptin, and the conservation of synteny between the mammalian leptin-locus and both zebrafish leptin loci further strengthens the assignment of orthology between zebrafish leptins and mammalian leptins.

An intriguing feature of the leptin-b sequence is the cysteine residue at the $\mathrm{N}$-terminus of $\boldsymbol{\alpha}$-helix-D. We designed $3 \mathrm{D}$ models of leptin-b to address the spatial orientation of this additional cysteine residue to see if this free cysteine would potentially be surface-exposed - and thus available for disulphide bridging - or is buried within the leptin's hydrophobic core. These models did not allow a firm prediction of the availability of this cysteine to form disulphide bridges, either within one leptin molecule or between two molecules because its position in the models is at the boundary of the protein surface and the protein core. It is possible that the residue is buried within the protein, and as a result not exposed to the environment and not available for disulphide interactions. The predicted mature leptin-b peptide contains no cysteine to form a disulphide bridge with the helix-D cysteine. A similar phenomenon has been observed for interleukin-11 genes in teleosts. Fish IL-11a and IL-11b both possess a single cysteine residue near the C-terminus, whereas mammalian IL-11 does not (Huising et al. 2005). Medaka leptin-b lacks an additional cysteine, indicating that this is not a universal feature among teleostean 
leptin-b genes. The elucidation of additional teleost leptin-b sequences will shed light on the uniqueness of this characteristic of zebrafish leptin-b.

We observed substantial differences between the expression patterns of zebrafish leptin-a and leptin-b. It is now generally accepted that leptin, in addition to its 'classical' role, is truly pleiotropic (Popovic et al. 2001, De Rosa et al. 2007). Indeed, in zebrafish, leptin-a and leptin-b are expressed in considerable amounts in the pituitary gland. We do not know the exact nature of the pituitary cells that (co-) express leptin in fish, nor the exact function of this leptin; in mammals, it is known that leptin is expressed in around $70 \%$ of the corticotropes and to a lesser extent in somatotropes (21\%), gonadotropes (29-33\%), and thyrotropes (32\%; Popovic et al. 2001). We propose that fish leptin produced in the pituitary gland must have additional, local (paracrine?) functions that allow zebrafish to maintain equilibrium in the face of challenges to homeostasis.

Whereas the high level of expression of leptin-a in the zebrafish liver conforms to the expression pattern observed for carp leptins, leptin-b is expressed at lower levels in the liver. Interestingly, it is this hepatic leptin-b mRNA level that decreases after fasting. The sheer size of the fish liver may guarantee a sufficient output of leptin(-b) protein, despite the relatively low leptin-b mRNA expression level.

Leptin-b shows the highest expression in the ovaries, which hardly express leptin-a. In mammals, leptin serves a function in the regulation of reproduction as $o b / o b$ mice treated with leptin recover fertility (Caprio et al. 2001, Archanco et al. 2003). Given the high expression of leptin-b in zebrafish ovaries, the reproductive function of leptin in this species may be carried out by leptin-b.

In addition to the marked differences in leptin's primary sequences between teleosts and mammals - which indicate potential differences in function - we now have demonstrated the existence of a second, equally divergent leptin in zebrafish and medaka that is likely a feature shared by more teleost fishes. The future challenge will be to unravel the physiological function of both leptin genes. In fact, the presence of two highly divergent orthologues of mammalian leptin in bony fish is testimony to the dynamic evolutionary history of leptin as it suggests the possibility of a redundant leptin network in teleosts. Furthermore, it adds fuel to the proposition that fish leptins, acting redundantly or independently, have acquired fundamentally different roles compared with mammalian leptins.

\section{Declaration of interest}

The authors declare that there is no conflict of interest that would prejudice the impartiality of this scientific work.

\section{Funding}

The authors did not receive additional funds for the research described in this paper.

\section{Acknowledgements}

We thank Dr Paul Kievit for advice regarding genome databases and Mr F A Tom Spanings for excellent fish husbandry.

\section{References}

Altschul SF, Madden TL, Schaffer AA, Zhang J, Zhang Z, Miller W \& Lipman DJ 1997 Gapped BLAST and PSI-BLAST: a new generation of protein database search programs. Nucleic Acids Research 25 3389-3402.

Archanco M, Muruzabal FJ, Llopiz D, Garayoa M, Gomez-Ambrosi J, Fruhbeck G \& Burrell MA 2003 Leptin expression in the rat ovary depends on estrous cycle. Journal of Histochemistry and Cytochemistry 51 1269-1277.

Ashwell CM, Czerwinski SM, Brocht DM \& McMurtry JP 1999 Hormonal regulation of leptin expression in broiler chickens. American Journal of Physiology 276 R226-R232.

Boswell T, Dunn IC, Wilson PW, Joseph N, Burt DW \& Sharp PJ 2006 Identification of a non-mammalian leptin-like gene: characterization and expression in the tiger salamander (Ambystoma tigrinum). General and Comparative Endocrinology 146 157-166.

Broberger C, Johansen J, Johansson C, Schalling M \& Hokfelt T 1998 The neuropeptide $\mathrm{Y} /$ agouti gene-related protein (AGRP) brain circuitry in normal, anorectic, and monosodium glutamate-treated mice. PNAS 95 15043-15048.

Canutescu AA, Shelenkov AA \& Dunbrack RL Jr 2003 A graph-theory algorithm for rapid protein side-chain prediction. Protein Science 12 2001-2014.

Caprio M, Fabbrini E, Isidori AM, Aversa A \& Fabbri A 2001 Leptin in reproduction. Trends in Endocrinology and Metabolism 12 65-72.

Crespi EJ \& Denver RJ 2006 Leptin ( $o b$ gene) of the South African clawed frog Xenopus laevis. PNAS 103 10092-10097.

Doyon C, Drouin G, Trudeau VL \& Moon TW 2001 Molecular evolution of leptin. General and Comparative Endocrinology 124 188-198.

Elias CF, Lee C, Kelly J, Aschkenasi C, Ahima RS, Couceyro PR, Kuhar MJ, Saper CB \& Elmquist JK 1998 Leptin activates hypothalamic CART neurons projecting to the spinal cord. Neuron 21 1375-1385.

Friedman-Einat M, Boswell T, Horev G, Girishvarma G, Dunn IC, Talbot RT \& Sharp PJ 1999 The chicken leptin gene: has it been cloned? General and Comparative Endocrinology 115 354-363.

Gorissen M, Flik G \& Huising MO 2006 Peptides and proteins regulating food intake: a comparative view. Animal Biology 56 447-473.

Hedges SB 2002 The origin and evolution of model organisms. Nature Reviews. Genetics 3 838-849.

Hoegg S \& Meyer A 2005 Hox clusters as models for vertebrate genome evolution. Trends in Genetics 21 421-424.

Huising MO, van der Meulen T, Flik G \& Verburg-van Kemenade BM 2004 Three novel carp CXC chemokines are expressed early in ontogeny and at nonimmune sites. European Journal of Biochemistry 271 4094-4106.

Huising MO, Kruiswijk CP, van Schijndel JE, Savelkoul HF, Flik G \& Verburg-van Kemenade BM 2005 Multiple and highly divergent IL-11 genes in teleost fish. Immunogenetics $\mathbf{5 7} 432-443$.

Huising MO, Geven EJ, Kruiswijk CP, Nabuurs SB, Stolte EH, Spanings FA, Verburg-van Kemenade BM \& Flik G 2006a Increased leptin expression in common Carp (Cyprinus carpio) after food intake but not after fasting or feeding to satiation. Endocrinology 147 5786-5797.

Huising MO, Kruiswijk CP \& Flik G $2006 b$ Phylogeny and evolution of classI helical cytokines. Journal of Endocrinology 189 1-25.

Huising MO, van Schijndel JE, Kruiswijk CP, Nabuurs SB, Savelkoul HF, Flik G \& Verburg-van Kemenade BM 2006c The presence of multiple and differentially regulated interleukin-12p40 genes in bony fishes signifies an expansion of the vertebrate heterodimeric cytokine family. Molecular Immunology 43 1519-1533.

Krieger E, Darden T, Nabuurs SB, Finkelstein A \& Vriend G 2004 Making optimal use of empirical energy functions: force-field parameterization in crystal space. Proteins $\mathbf{5 7}$ 678-683. 
Kumar S, Tamura K \& Nei M 2004 MEGA3: integrated software for molecular evolutionary genetics analysis and sequence alignment. Briefings in Bioinformatics 5 150-163.

Kurokawa T, Uji S \& Suzuki T 2005 Identification of cDNA coding for a homologue to mammalian leptin from pufferfish, Takifugu rubripes. Peptides $26745-750$

Larhammar D \& Risinger C 1994 Molecular genetic aspects of tetraploidy in the common carp Cyprinus carpio. Molecular Phylogenetics and Evolution 3 59-68.

McGuffin LJ \& Jones DT 2003 Improvement of the GenTHREADER method for genomic fold recognition. Bioinformatics 19 874-881.

Metz JR, Geven EJ, van den Burg EH \& Flik G 2005 ACTH, alpha-MSH, and control of cortisol release: cloning, sequencing, and functional expression of the melanocortin-2 and melanocortin-5 receptor in Cyprinus carpio. American Journal of Physiology. Regulatory, Integrative and Comparative Physiology 289 R814-R826.

Morton GJ, Cummings DE, Baskin DG, Barsh GS \& Schwartz MW 2006 Central nervous system control of food intake and body weight. Nature 443 289-295.

Popovic V, Damjanovic S, Dieguez C \& Casanueva FF 2001 Leptin and the pituitary. Pituitary 4 7-14.

De Rosa V, Procaccini C, Cali G, Pirozzi G, Fontana S, Zappacosta S, La Cava A \& Matarese G 2007 A key role of leptin in the control of regulatory T cell proliferation. Immunity 26 241-255.

Schwartz MW, Woods SC, Porte D Jr, Seeley RJ \& Baskin DG 2000 Central nervous system control of food intake. Nature 404 661-671.

Sharp PJ, Dunn IC, Waddington D \& Boswell T 2008 Chicken leptin. General and Comparative Endocrinology 158 2-4.

Taouis M, Chen JW, Daviaud C, Dupont J, Derouet M \& Simon J 1998 Cloning the chicken leptin gene. Gene 208 239-242.
Taylor JS, Braasch I, Frickey T, Meyer A \& Van de Peer Y 2003 Genome duplication, a trait shared by 22000 species of ray-finned fish. Genome Research 13 382-390.

Thompson JD, Higgins DG \& Gibson TJ 1994 CLUSTAL W: improving the sensitivity of progressive multiple sequence alignment through sequence weighting, position-specific gap penalties and weight matrix choice. Nucleic Acids Research 22 4673-4680.

Volff JN 2005 Genome evolution and biodiversity in teleost fish. Heredity 94 280-294.

Volkoff H, Canosa LF, Unniappan S, Cerda-Reverter JM, Bernier NJ, Kelly SP \& Peter RE 2005 Neuropeptides and the control of food intake in fish. General and Comparative Endocrinology 142 3-19.

Zardoya R \& Doadrio I 1999 Molecular evidence on the evolutionary and biogeographical patterns of European cyprinids. Journal of Molecular Evolution 49 227-237.

Zhang Y, Proenca R, Maffei M, Barone M, Leopold L \& Friedman JM 1994 Positional cloning of the mouse obese gene and its human homologue. Nature 372 425-432.

Zhang F, Basinski MB, Beals JM, Briggs SL, Churgay LM, Clawson DK, DiMarchi RD, Furman TC, Hale JE, Hsiung HM et al. 1997 Crystal structure of the obese protein leptin-E100. Nature 387 206-209.
Received in final form 4 March 2009
Accepted 13 March 2009
Made available online as an Accepted Preprint 16 March 2009 